\title{
O ABANDONO DO PATRIMÔNIO ARQUEOLÓGICO SUBAQUÁTICO NO BRASIL. UM PROBLEMA PARA A ARQUEOLOGIA BRASILEIRA*
}

O objetivo desta nota é chamar atenção à problemática que envolve a preservação do patrimônio arqueológico subaquático no Brasil e, também, apontar possíveis soluções aos problemas a serem aqui levantados, na tentativa de reverter o quadro de abandono em que se encontram esses bens culturais sob nossas águas (marítimas e/ou interiores).

O patrimônio que se encontra no fundo das águas está sujeito a uma violação ainda maior do que aqueles que se encontram em superfície. Existe uma depredação contínua, sobretudo dos naufrágios marítimos, proveniente da pouca importância dada a esses bens culturais por parte dos órgãos responsáveis pela gestão patrimonial nacional. Conseqüentemente, esta situação é caracterizada por uma total falta de conscientização do público comum, quanto à importância desse patrimônio. Desta forma, mergulhadores - amadores e/ou profissionais - caçadores de tesouros ou não, que visitam constantemente muitos desses sítios, consideram esses bens culturais como alvos fáceis e desprotegidos, frutos de suas descobertas pessoais.

Como lidar com este desrespeito patrimonial?

Com um litoral que se estende por mais de $8.500 \mathrm{~km}$, palco de milhares de naufrágios em quase 500 anos de história trágico-marítima, com águas interiores que representam uma das maiores redes fluviais do mundo, temos uma certeza: o Brasil desconhece os bens culturais submersos em suas águas.

Quanto se perdeu e ainda se perde de informações importantíssimas para a arqueologia brasileira (pré-histórica e histórica)? Quantos sítios arqueológicos se encontram, por um motivo ou outro, ${ }^{1}$ encobertos pelas águas? E as represas, qual o impacto delas sobre o estado de conservação dos sítios arqueológicos?

(*) Parte deste trabalho foi apresentado no Seminário Internacional: "Caminhos da Preservação II: Usos do Patrimônio", realizado no MuBE (Museu Brasileiro da Escultura) São Paulo - SP, de 27 a 30 de julho de 1997 - Organização: ICOMOS-BRASIL

(1) Destroços e/ou ruínas de embarcações naufragadas; instalações portuárias marítimas e/ou fluviais; ocupações pré-
Enquanto em vários países do mundo os arqueólogos aprenderam a mergulhar com o objetivo explícito de estender o alcance de suas pesquisas científicas ao ambiente aquático, no Brasil, só o fato de se pensar no objeto de pesquisa embaixo d'água, acabou por criar universos distintos entre a ciência e a aventura submarina. Tal atitude é fortemente baseada na desinformação sobre a arqueologia brasileira - visto que a arqueologia subaquática hoje, nada mais é que a arqueologia praticada no ambiente aquático - e na ineficácia da legislação - lei nº 7.542 de 1986 com Portaria Interministerial (Ministério da Marinha e Ministério da Cultura) $\mathrm{n}^{\circ} 69$, de 23 de janeiro de 1989 , que enfatiza serem todos os bens artísticos, históricos e arqueológicos encontrados submersos pertencentes à União, contudo, não deixando claro o que é um sítio arqueológico submerso e, menos ainda, o por quê das diferenças entre os bens submersos e os bens encontrados em superfície. ${ }^{2}$ Desta forma, foram beneficiados diretamente os mergulhadores aventureiros, que acabaram dominando por completo o acesso ao patrimônio submerso. Este domínio é tão marcante, que muitos deles se ofendem quando sabem de nossas intenções preservacionistas em relação ao patrimônio submerso, por o considerarem suas propriedades particulares.

Para se ter uma idéia da gravidade do problema, existem as depredações clandestinas justificadas na obrigatoriedade da lei, da necessidade de

históricas e históricas que foram absorvidas pelas flutuações do nível marinho; poços ou lagos utilizados em rituais; lugares que se tornaram submersos pela ação antrópica (represas, canais, açudes, etc.), etc..

(2) Normas para Procedimentos Ligados à Pesquisa e Proteção de Bens Arqueológicos Submersos, nos Termos da Lei $n^{\circ} 7.542$ de Setembro de 1986 - Diário Oficial 26/01/89. “4) Exploração Científica

4.1) A Autorização para exploração científica de áreas ou locais que contenham coisas ou bens afundados, submersos, (...), será competência do Ministério da Marinha, ouvido o Ministério da Cultura. 
se entregar os objetos retirados à União, e também as depredações que podemos chamar de oficiais, pois é muito comum a deliberação de autorização para explorações dos bens culturais submersos pela própria Marinha do Brasil, responsável pela legislação vigente, sem a exigência preliminar de um projeto coerente de pesquisa sistemática com base metodológica, acabando por favorecer empresas e grupos particulares de atividades submarinas, totalmente despreparados de quaisquer formações necessárias para tais intervenções.

Sendo assim, não podemos mais permitir que estes abusos prejudiciais ao patrimônio se mantenham como se fossem problemas alheios aos demais encontrados em superfície. É dever de todos nós arqueólogos incluirmos em toda a temática preservacionista do patrimônio os bens culturais submersos. Do contrário, enquanto houver esta lacuna entre "versão seca" e "versão molhada" do patrimônio, numerosos sítios arqueológicos submersos estarão desaparecendo literalmente sob nossos olhos.

Cabe ressaltar, para um maior esclarecimento, diante desta diferença de atitude patrimonial, que o patrimônio arqueológico subaquático não se resume aos navios afundados nos oceanos como enfatizam nossa legislação e a mídia sensacionalista. Ele é constituído por todos os bens móveis ou imóveis, testemunhos de uma ação humana situados inteiramente ou em parte no mar, nos rios,

4.2) Para cada exploração científica, o Ministério da Marinha designará uma Comissão Interministerial que terá por propósito definir, dentre a totalidade do material resgatado, as peças de valor artístico, de interesse histórico ou arqueológico. 4.2.1) A Comissão Interministerial terá a seguinte constituição: 3 membros indicados pelo MinC. e 3 membros indicados pelo MM.

4.2.2) As indicações para os membros da Comissão Interministerial devem recair sobre pessoal habilitado nas áreas de arqueologia, história da arte, e outras áreas afins.

4.2.3) A presidência da Comissão Interministerial caberá a um dos representantes do Ministério da Marinha.

4.2.4) As decisões da Comissão Interministerial serão tomadas por consenso.

4.2.5) Na hipótese de não ocorrer consenso entre os membros da Comissão Interministerial a decisão será tomada por votação.

4.2.6) Em caso de empate na votação, caberá ao Presidente da Comissão Interministerial a decisão final sobre o assunto. 4.2.7) O material resgatado, definido pela Comissão Interministerial como de valor artístico de interesse histórico ou arqueológico, permanecerá no domínio da União, conforme estabelecido no Art. 20 da Lei n ${ }^{\circ} 7.542 / 86 . "$ nos lagos, nas lagoas, nos cais, nas valas, nos cursos de água, nos canais, nas represas, nos reservatórios artificiais, nos poços e outros planos de água, em zonas de maré, manguezais, ou quaisquer outras zonas inundadas periodicamente, ou recuperados num tal meio, ou encontrados em margens atualmente assoreadas. ${ }^{3}$

Outro problema relativo aos ataques a esse patrimônio é a questão da conservação dos objetos retirados do ambiente aquático. Eles necessitam de tratamento especial logo que tomam contato com a superfície, para não se deteriorarem. Assim, é vítima de um processo duplamente destrutivo: quando o objeto é arrancado de seu contexto; e quando desaparece por completo. Infelizmente, é muito comum entre mergulhadores que se divertem nos finais de semana arrancando peças de navios, o abandono de seus souvenirs nas lixeiras dos clubes náuticos logo após desembarcarem da aventura ou, com certeza, alguns dias mais tarde nas lixeiras de suas casas. Já a depredação feita por grupos organizados - nacionais e/ou estrangeiros - de caça ao tesouro, não seguem esta regra, pois são equipados com o que há de melhor no mercado para garantir a integridade desses objetos, valorizandoos no mundo dos colecionadores.

Como podemos perceber, a triste realidade subaquática brasileira é crítica. Por isso, não podermos continuar nesta distinção ao patrimônio cultural que se encontra submerso. O que fazer então? E como fazê-lo?

Existe no quadro de comitês internacionais do ICOMOS (International Council on Monuments and Sites), o Comitê Internacional do Patrimônio Cultural Subaquático (ICUCH ${ }^{4}$ - International Committee on the Underwater Cultural Heritage), que se ocupa das discussões sobre o patrimônio internacional submerso. E é com base nos objetivos descritos em suas regras de procedimentos, que acreditamos poder reverter aos poucos este processo destrutivo que envolve o nosso patrimônio aquático.

Para uma melhor compreensão desses objetivos citados, apresentaremos na íntegra a tradução

(3) Definição elaborada pelo autor com base em Convenções e Legislações Internacionais (UNESCO, ICUCH - ICOMOS, Convenção Européia, Legislação Portuguesa, Legislação Francesa).

(4) Este comitê foi estabelecido de acordo com o artigo 14 dos Estatutos ICOMOS, por resolução do Executivo (ICOMOS) em novembro de 1991. 
do item 3, referente ao Objetivo contido nas Regras de Procedimentos do ICOMOS - Comitê Internacional do Patrimônio Cultural Subaquático: ${ }^{5}$

\section{Objetivo}

O objetivo particular do comitê é promover a cooperação internacional em identificar, proteger e conservar os sítios de patrimônio cultural subaquático e avisar o ICOMOS do desenvolvimento e implementação de programas nesse campo.

3.1 O objetivo do Comitê inclui, mas não está limitado a:

3.1.1 Estímulo ao interesse internacional e conservação do patrimônio cultural subaquático mundial associado ao governo e instituições privadas, profissionais liberais e ao público em geral.

3.1.2 Promover o inventário sistemático do patrimônio cultural subaquático mundial.

3.1.3 Desenvolvimento e promoção de estratégias efetivas para conservação, manejamento e apresentação do patrimônio cultural subaquático mundial.

3.1.4 Promover métodos de aperfeiçoamento e critérios para localização, exploração, registro e intervenção em sítios de patrimônio cultural subaquático.

3.1.5 Estabelecimento de critérios para o treinamento e qualificação de profissionais envolvidos com a conservação e o manejamento de sítios de patrimônio cultural subaquático.

3.1.6 A troca de experiência e perícia na conservação (preservação) de sítios de patrimônio cultural subaquático.

Alguns de nossos projetos já estão em andamento com base nos objetivos e preceitos do Comitê Internacional do Patrimônio Cultural Subaquático (ICUCH) e outros em fase de planejamento estratégico para intervenções em áreas inundadas artificialmente (barragens, represas, açudes, etc.):

- O projeto de pesquisa: “A Arqueologia Subaquática e sua aplicação à Arqueologia Brasileira: o exemplo do Baixo Vale do Ribeira de

(5) In Rules of Procedure ICOMOS - International Committee on Underwater Cultural Heritage Incorporated (p. 2).

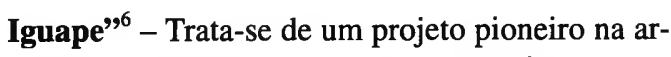
queologia brasileira que integra a pesquisa arqueológica subaquática sistemática às pesquisas arqueológicas terrestres que vêm sendo realizadas no Baixo Vale do Ribeira, com o objetivo de não só ampliar a extensão do potencial arqueológico (préhistórico e histórico) da região para o domínio submerso, como também oferecer, através de uma síntese de exemplos sobre métodos e técnicas desenvolvidos e utilizados nas pesquisas de arqueologia subaquática de vários países do mundo, subsídios que supostamente poderão servir como um "manual" para futuros trabalhos a serem realizados no Brasil;

- O "Projeto Porto Grande de Iguape" Vem sendo realizado por Scatamacchia, Demartini e Rambelli, na cidade de Iguape - SP, e representa claramente a integração da pesquisa arqueológica realizada no ambiente aquático às pesquisas terrestres, devido à localização de suas antigas estruturas de instalações portuárias: parte em terra, parte no limite água/superfície e parte totalmente submersa. O Porto Grande será transformado em um Museu de Sítio;

- O "Projeto NAUI (National Association of Underwater Instructors) Brasil de Arqueologia Subaquática" - adaptado do programa norte americano de Arqueologia Subaquática NAUI à realidade brasileira, ${ }^{7}$ tem o objetivo de formar, sensibilizar e conscientizar o mergulhador esportivo brasileiro sobre a importância da preservação do patrimônio cultural submerso (Educação Patrimonial) e também ensinar as atividades do mergulho autônomo científico aos pesquisadores brasileiros, rompendo, assim, com o pensamento errôneo das dificuldades de atuação científica no ambiente aquático. Cabe ressaltar, nas palavras do arqueólogo norte-americano George Bass (1966), que "é mais fácil ensinar um arqueólogo a mergulhar, que ensinar arqueologia a um mergulhador"

- O "Projeto Águas Interiores" - Possibilitará o estudo sistemático e a elaboração de um laudo técnico sobre o estado de conservação de diferentes sítios arqueológicos brasileiros (pré-históricos e/ou históricos) que se tornaram submersos pela ação antrópica.

(6) Dissertação de mestrado do autor, sob orientação da Profa. Dra. Maria Cristina Mineiro Scatamacchia (MAE - USP), em fase de conclusão.

(7) Adaptação feita pelo autor. 
Muitos outros projetos aguardam o momento certo para serem colocados em prática, dentre eles, o mais importante, o "Projeto Nacional de cadastramento sistemático dos sítios arqueológicos subaquáticos (águas marítimas e/ou interiores)". Pois acreditamos que só um inventário de âmbito nacio- nal poderá garantir a proteção destes bens culturais. Mas, para tal realização, é preciso somar nossas forças e contarmos com o apoio da arqueologia brasileira, através da SAB (Sociedade de Arqueologia Brasileira), assim como do IPHAN, do ICOMOS Brasil, do ICUCH, da Marinha do Brasil, etc..

Gilson Rambelli** 